\title{
A Perspective on the Relevance of Psychological Science and Some Implications for the Reform Movement
}

\author{
Jonathon McPhetres $^{1 *}$
}

Word count: 1,465

1 Jonathon McPhetres is a $\mathrm{PhD}$ candidate at the University of Rochester, Department of Clinical and Social Science in Psychology, Rochester, NY, USA

*Correspondence can be addressed to Jonathon McPhetres: jon.mcphetres@ gmail.com

Special thanks to Viet Duong and Phu Pham who accessed the data for me; special thanks to Thuy-vy Nguyen who provided comments on the drafts of this manuscript.

Data described herein can be accessed at:

https://osf.io/bca4v/?view_only=6e3a3f379c1f4a86bbdec04fbe69746d 


\begin{abstract}
Concerns about the generalizability, veracity, and relevance of social psychological research often resurface within psychology. While many changes are being implemented to improve the integrity of published research and to clarify the publication record, mixed attention has been given to the questions of relevance. In this short commentary, I offer my perspective on questions of relevance and present some data from the website Reddit. The data show that people care greatly about research dealing with humans: links tagged as psychology, social sciences, and health are upvoted more than other categories. Within the category of psychology, articles were coded based on the topic of research. Articles dealing generally with social psychological topics are among the highest in number and upvotes on the subreddit r/science. However, upvotes on Reddit are unrelated to metrics used by researchers to gauge importance (e.g., impact factor, journal rankings and citations), suggesting a disconnect between what psychologists and lay-audiences may see as relevant. I interpret these data in light of the replication crisis and suggest that such a spotlight on our field puts greater importance on the need for reform. Whether we like it or not, people care about, share, and use psychological research in their lives, which means that a priority of the field should be to ensure that our findings are reported accurately and transparently.
\end{abstract}




\section{A Perspective on the Relevance of Psychological Science and}

\section{Some Implications for the Replication Movements}

As a grad student in my 30s, this is my first crisis. However, I am assured time and again by senior researchers that the current crises facing psychology are nothing new. I have read previous and recent commentaries (e.g., Sherif, 1970; Silverman, 1971) with interest because they provide a window into a past version of psychology which mirrors the psychology I know now. While little changes came out of these crises in the 1970s and 1980s, many changes are being implemented now to identify, correct, and avoid false positives in the literature. For example, journals are implementing requirements for power analyses and sample sizes, preregistration is becoming more commonplace, and large-scale replication projects are clarifying what we do and do not know about human psychology.

However, one question posed then (Silverman, 1971) and now (Giner-Sorolla, 2019; Lilienfeld, 2012) which receives mixed attention is whether psychological research is relevant. Are psychologists asking the kinds of questions that are important and interesting to non-psychologists? As a researcher who is profoundly interested in what people think of science and scientists, I naturally gravitate towards this question. As a millennial, I naturally turned to the website Reddit to examine what research is relevant and important to people.

Reddit is a free social media website with a large worldwide audience (500+ million subscribers).

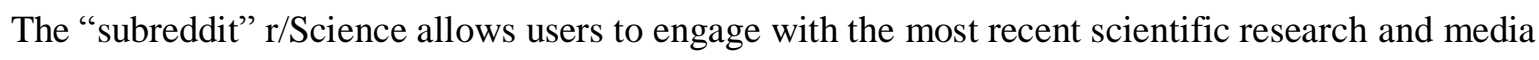
coverage; all users are subscribed by default to this subreddit. Anyone can post content, comment, "upvote" content they like, and can "downvote" content they do not like. Such a metric is a straightforward method of assessing whether psychological research is interesting to the average user.

Data were downloaded from Reddit which include posts to r/Science from all of 2017. The graph below (Fig 1) depicts the average number of upvotes per discipline. Posts tagged with "Psychology" have the highest mean upvotes $(M=2,759, S E=302.95)$ followed closely by those tagged with "Social Science" $(M=2,602, S E=447.34)$ and "Health" $(M=2,525, S E=253.35)$. Clearly, people are interested in research which deals with humans and psychology is the epitome of this. 
Fig. 1. Mean upvotes by discipline tag.

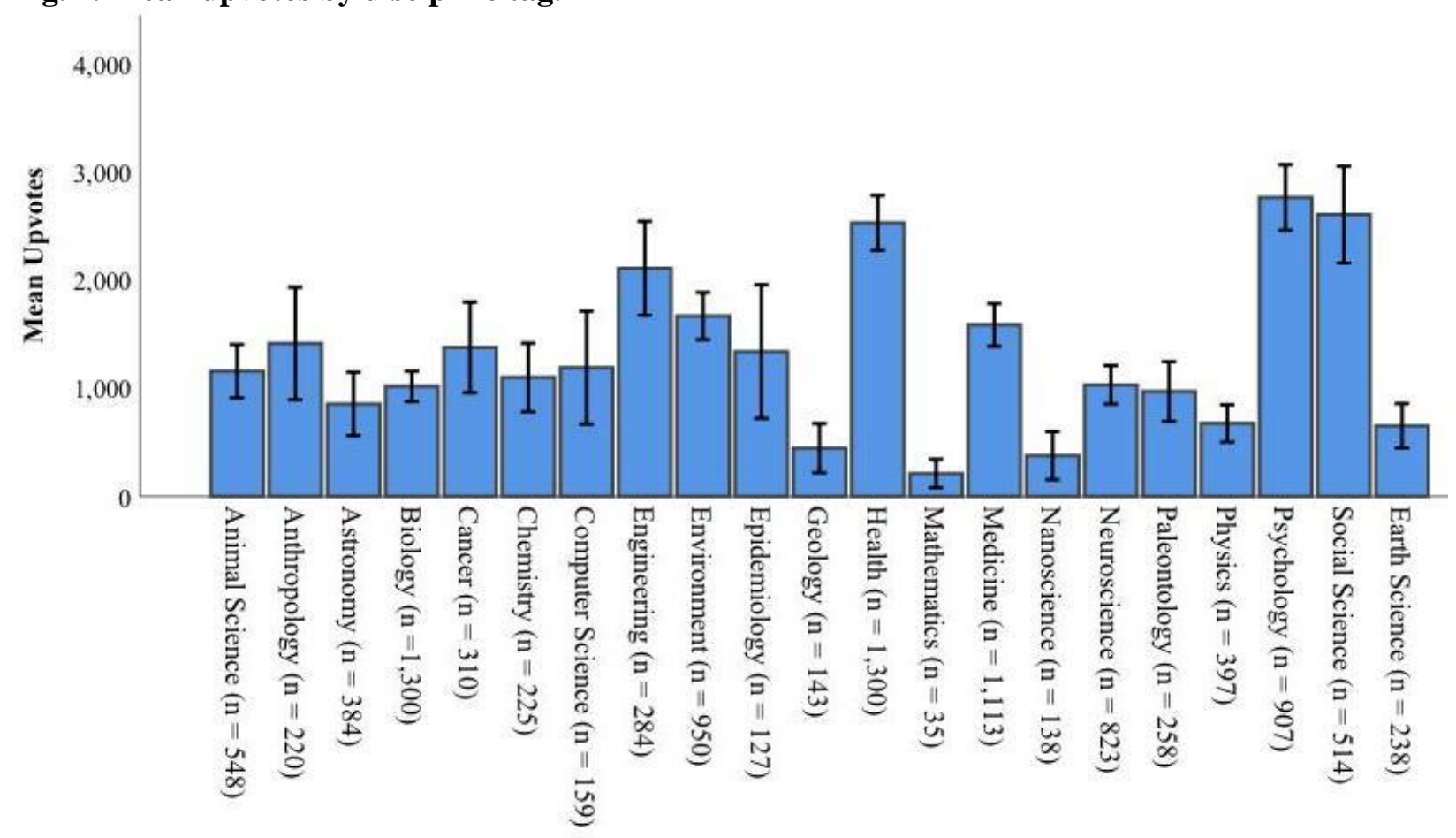

Note: Error bars represent +/- $1 \mathrm{SE}$.

Breaking down the data even further, I had four research assistants categorize each psychology post into a broad sub-discipline (e.g., social, developmental, clinical, or cognitive) based on the topic of the research as indicated by title of the post. As shown in Figure 2, developmental articles $(n=100)$ received the highest average votes. Those categorized as social were the most in number $(n=540)$ with the second-highest average upvotes; next was clinical psychology $(n=218)$. Cognitive-neuroscience articles $(n=49)$ were the fewest in number and upvotes. 
Fig 2. Mean upvotes by psychology sub-discipline.

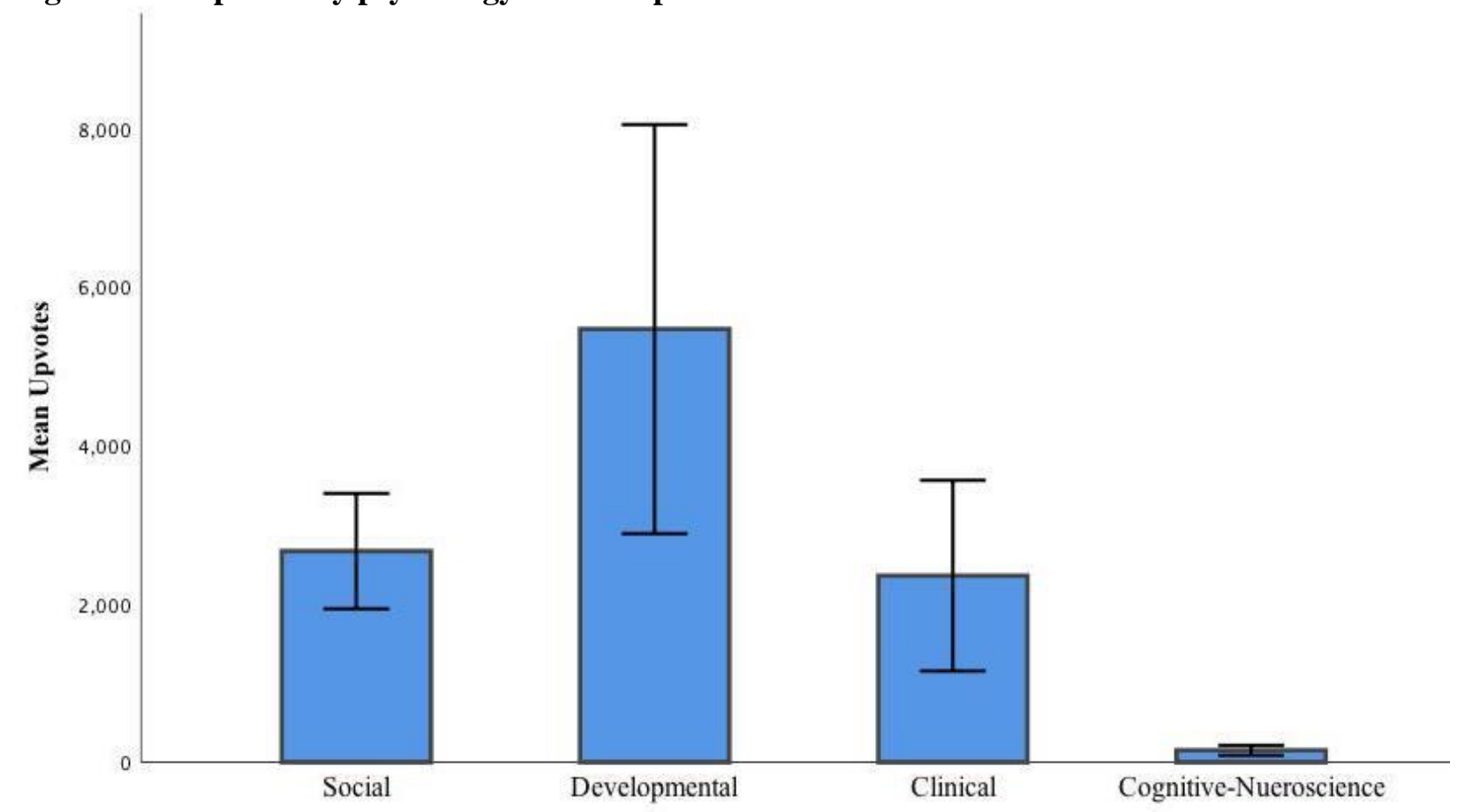

Note: Error bars represent +/- 1 SE.

We were also able to identify the journal within which each article was published and locate the metrics for that journal. The first thing to notice about these data are that the posts with the highest number of upvotes came from a variety of journals (see Table 1), none of which are considered the highest-ranking journals in social psychology. However, many of the top-tier journals frequently had their articles posted on Reddit; looking at the journals which had the most posts (see Figure 3) we see that journal status does not necessarily indicate public interest. The Journal of Experimental Social Psychology had some of the most upvoted articles while Psychological Science and Journal of Personality and Social Psychology, for example, had lower mean upvotes within a tighter range. 
Table 1. Top 10 most upvoted articles/posts within social psychology

\begin{tabular}{cll}
\hline Upvotes & \multicolumn{1}{c}{ Journal } & \multicolumn{1}{c}{ Authors } \\
\hline 74,636 & Journal of Applied Research in Memory and Cognition & (Taylor, Wood, \& Garry, 2017) \\
57,898 & $\begin{array}{l}\text { Journal of Experimental Social Psychology and } \\
\text { Perspectives on Psychological Science }\end{array}$ & $\begin{array}{l}\text { (Frimer, Skitka, \& Motyl, 2017) and } \\
\text { Doehl, Hellmer, Johansson \& Gredebäck, } \\
\text { 2017) }\end{array}$ \\
54,090 & Frontiers in Psychology & Robinson, Anderson \& White, 2017 \\
52,571 & Sex Roles & Cowgill, Rios, \& Simpson, 2017 \\
48,250 & Journal of Experimental Social Psychology & Weiser et al., 2017 \\
46,692 & Personality and Individual Differences & LaFrance \& Cuttler, 2017 \\
44,505 & Consciousness and Cognition & Zitek \& Jordan, 2017 \\
43,125 & Social Psychological and Personality Science & Brienza \& Grossman, 2017 \\
39,140 & Proceedings of the Royal Society B: Biological Sciences & Ståhl \& van Prooijen, 2018 \\
37,583 & Personality and Individual Differences &
\end{tabular}

Fig. 3. Mean and range of upvotes for psychology journals with the most posts on Reddit.

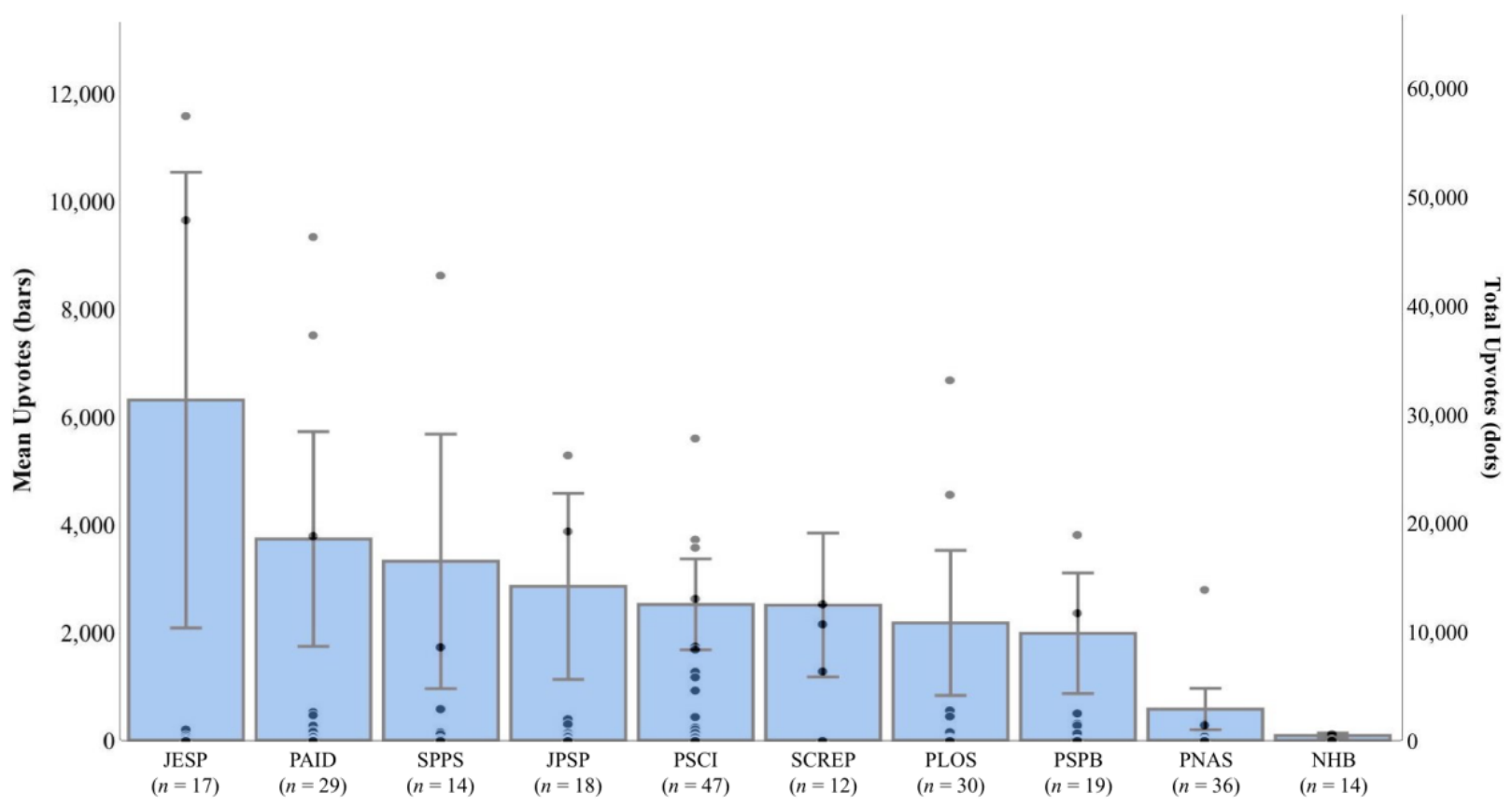

Note: Mean upvotes are indicates by bars corresponding to the left axis; range of upvotes are indicated by dots corresponding to the right axis. Error bars indicate $+/-1 S E$.

Examining this data at the journal level changes the information we can glean. Not only are we asking what kinds of psychological research lay people find interesting, but we can now see whether the questions of interest and relevance to this audience are in any way related to metrics of interest and relevance used by social psychologists: it appears they are not. Reddit upvotes were simply not correlated with impact factor or journal rankings (see Table 2). Metrics such as impact factor and journal rankings 
are often factored into decisions for hiring, tenure promotions, and grants (but, see Abambres, Ribeira, Sousa, \& Lantsoght, 2018 for an argument as to why impact factors are poor metrics of researcher performance). However, these results further indicate that the kind of research that makes it into top journals is not often the same stuff that makes the front page.

Table 2. Correlations between Reddit upvotes and journal metrics for social psychology articles.

\begin{tabular}{lcccccccc}
\hline & $\mathbf{1}$ & $\mathbf{2}$ & $\mathbf{3}$ & $\mathbf{4}$ & $\mathbf{5}$ & $\mathbf{6}$ & $\mathbf{7}$ & $\mathbf{8}$ \\
\hline $\mathbf{1}$ Reddit Upvotes & & & & & & & & \\
$\mathbf{2}$ Impact Factor & -0.060 & & & & & & \\
3 Journal Rank (overall) & 0.009 & $-.458^{* *}$ & & & & & \\
4 Journal Rank (social psyc.) & -0.052 & $-.574^{* *}$ & $.994^{* *}$ & & & & \\
$\mathbf{5}$ Journal Rank (social science) & -0.09 & $-.624^{* *}$ & $.995^{* *}$ & $.994^{* *}$ & & & \\
6 Journal Rank (psychology) & 0.078 & $-.657^{* *}$ & $.988^{* *}$ & $.998^{* *}$ & $.974^{* *}$ & & & \\
$\mathbf{7}$ SJR Score & -0.056 & $.851^{* *}$ & $-.535^{* *}$ & $-.702^{* *}$ & $-.654^{* *}$ & $-.733^{* *}$ & & \\
8 Quartile & 0.038 & $-.114^{*}$ & $.789^{* *}$ & $.759^{* *}$ & $.794^{* *}$ & $.668^{* *}$ & $-.227^{* *}$ & \\
$\mathbf{9}$ Cites 3/years & -0.029 & -0.038 & 0.032 & $-.675^{* *}$ & $-.470^{* *}$ & -0.003 & $-.102^{*}$ & -0.075 \\
\hline
\end{tabular}
Note: $* * p<.01,{ }^{*} p<.05$.

What do these results mean? First, these data show that people care deeply about research which deals with humans_-namely psychological research, and especially social psychological research. Second, these data point to a disconnect between the metrics of evaluation used by scientists and laypeople. These data show that the research people care deeply about is not the same research that scientists care deeply about — at least not according to any of the metrics scientists use. Put differently, scientists may be concerned with theory and lay people may be concerned with application; maybe scientists want something to build their new findings on and lay people want findings that apply in the present moment. Another possibility is that scientists see a different goal and a different audience for their science. Whatever the reason, I think these data suggest that people find psychological research interesting and perhaps "relevant" despite concerns otherwise.

Of course, the data presented here are not meant to be prescriptive; that is, I would not recommend that scientists go on Reddit to identify the areas that lay people find interesting and start 
conducting their research accordingly. Clearly the argument can be made that pursuit of flashy and surprising findings is one factor leading to large-scale non-replicability. Instead, perhaps we can reflect on who should be the beneficiaries of our science. As psychology is the field aiming to explain human behaviors (Rad, Martingano, \& Ginges, 2018), should we be producing findings that apply to people's life in the present? From this data, it appears that psychology as a whole does fulfill that role whether we like it or not.

Therefore, these findings have some important implications for issues around the replication crisis and the integrity of our research. People will pay attention to our findings, they will share them online, they will talk about them, and they will use them. We then have a responsibility to make sure that our published findings are accurate and hold up to scrutiny. We have a responsibility to make sure that we share data, we are transparent in our analyses, and that we minimize the reporting of false-positives. We have a responsibility to make sure that we are communicating our results accurately because whether we like it or not, our research does not just go to researchers.

In conclusion (and as a disclaimer) I approached this data expecting to find that psychology was not as interesting to lay people as some other fields. I expected this for several reasons. First, because my own research seems to suggest that science is viewed less positively than we scientists would like to admit. Second, because psychology is quite complicated, esoteric, and long-winded (Witte \& Brandt, 2011), as well as overly theoretical and less descriptive (Rozin, 2001), and increasingly complex (Quiñones-Vidal, Loźpez-García, Peñaranda-Ortega, \& Tortosa-Gil, 2004). This combination of characteristics seems less likely to attract the average reader but, for some reason, promotes further complexity and long-windedness as though complexity were a metric of quality. Third, I have on occasion given in to my pessimism when looking at large scale replication failures and wondered "how can anyone care about psychology if we, the people who carry out the research, can't even trust it?" Nonetheless, I was pleased to find that Reddit users upvote psychology research as much as they do. Finally, I did not preregister any of these analyses, nor did I conduct any confirmatory tests. I simply present some descriptive results and take them at face-value. 
The take-home message is that there both is and isn't a crisis of relevance. In one sense, there may be a crisis because the kinds of research that lay people find interesting is not the kind of research that scientists find interesting or important; this disconnect may be concerning. However, people (at least users of Reddit) clearly find some psychological research interesting enough if it is tied for the highest average upvotes. With that message in mind, perhaps we should focus on the other crisis - the one where most psychology research is underpowered, ungeneralizable, and not replicable (Camerer et al., 2018; Ioannidis, 2005; Klein et al., 2018; Open Science Collaboration, 2015; Rad et la., 2018; Simmons, Nelson, \& Simonsohn, 2011, 2018) — because even the least interesting research needs to be accurate. Moving forward, the goal of researchers (indeed, the field) should be to minimize false positives and to reduce (or prevent) questionable research practices in published findings so that the public has access to accurate research which actually informs us about human nature. Many suggestions have been proposed to address this problem (e.g., preregistration, transparent reporting, data sharing) and I hope to see them adopted more widely.

As a graduate student, I find this a very exciting and stimulating time to be developing my career as a researcher. I hope that we, psychologists, can continue to garner interest and that we can continue to ask the right questions. At the same time, I hope the field can continue to improve the methods we use and the way we report our findings because people are watching eagerly.

\section{Data availability}

Data described herein can be accessed at:

https://osf.io/bca4v/?view_only=6e3a3f379c1f4a86bbdec04fbe69746d

\section{Competing Interests}

The author declares no conflicts of interest. 


\section{References}

Abambres, M., Ribeiro, T., Sousa, A., \& Lantsoght, E. (2018). Research Counts, Not the Journal. OSF Preprints. DOI: 10.31219/osf.io/4z39a

Brienza, J. P., \& Grossmann, I. (2017). Social class and wise reasoning about interpersonal conflicts across regions, persons and situations. Proceedings of the Royal Society B: Biological Sciences, 284(1869), doi: 10.1098/rspb.2017.1870.

Camerer, C. F., Dreber, A., Holzmeister, F., Ho, T. H., Huber, J., Johannesson, M., ... \& Altmejd, A. (2018). Evaluating the replicability of social science experiments in Nature and Science between 2010 and 2015. Nature Human Behaviour, 2(9), 637, https://doi.org/10.1038/s41562-018-0399-z

Cowgill, C. M., Rios, K., \& Simpson, A. (2017). Generous heathens? Reputational concerns and atheists' behavior toward Christians in economic games. Journal of Experimental Social Psychology, 73, 169-179. https://doi.org/10.1016/j.jesp.2017.06.015

Ditto, P. H., Liu, B. S., Clark, C. J., Wojcik, S. P., Chen, E. E., Grady, R. H., ... \& Zinger, J. F. (2018). At least bias is bipartisan: A meta-analytic comparison of partisan bias in liberals and conservatives. Perspectives on Psychological Science, doi: 10.1177/1745691617746796.

Frimer, J. A., Skitka, L. J., \& Motyl, M. (2017). Liberals and conservatives are similarly motivated to avoid exposure to one another's opinions. Journal of Experimental Social Psychology, 72, 112. https://doi.org/10.1016/j.jesp.2017.04.003

Giner-Sorolla, R. (2019). From crisis of evidence to a "crisis" of relevance? Incentive-based answers for social psychology's perennial relevance worries. European Review of Social Psychology, 30(1), 1-38, 10.31234/osf.io/nua9s.

Hoehl, S., Hellmer, K., Johansson, M., \& Gredebäck, G. (2017). Itsy bitsy spider...: infants react with increased arousal to spiders and snakes. Frontiers in psychology, 8, 1710, https://doi.org/10.3389/fpsyg.2017.01710. 
Ioannidis, J. P. (2005). Why most published research findings are false. PLoS medicine, 2(8), e124, ttps://doi.org/10.1371/journal.pmed.0020124.

Klein, R. A. (2018). Many Labs 2: Investigating variation in replicability across sample and setting. 10.31234/osf.io/9654g.

LaFrance, E. M., \& Cuttler, C. (2017). Inspired by Mary Jane? Mechanisms underlying enhanced creativity in cannabis users. Consciousness and cognition, 56, 68-76, doi: 10.1016/j.concog.2017.10.009.

Lilienfeld, S. O. (2012). Public skepticism of psychology: Why many people perceive the study of human behavior as unscientific. The American Psychologist, 67, 111-129, doi: 10.1037/a0023963.

Open Science Collaboration. (2015). Estimating the reproducibility of psychological science. Science, 349(6251), DOI: 10.1126/science.aac4716.

Quiñones-Vidal, E., Loźpez-García, J. J., Peñaranda-Ortega, M., \& Tortosa-Gil, F. (2004). The nature of social and personality psychology as reflected in JPSP, 1965-2000. Journal of Personality and Social Psychology, 86(3), 435, 10.1037/0022-3514.86.3.435.

Rad, M. S., Martingano, A. J., \& Ginges, J. (2018). Toward a psychology of Homo sapiens: Making psychological science more representative of the human population. Proceedings of the National Academy of Sciences, 115(45), 11401-11405, https://doi.org/10.1073/pnas.1721165115.

Robinson, S., Anderson, E., \& White, A. (2018). The bromance: Undergraduate male friendships and the expansion of contemporary homosocial boundaries. Sex Roles, 78(1-2), 94-106, 10.1007/s11199-017-0768-5.

Rozin, P. (2001). Social psychology and science: Some lessons from Solomon Asch. Personality and Social Psychology Review, 5(1), 2-14, https://doi.org/10.1207/S15327957PSPR0501_1.

Sherif, M. (1970). On the relevance of social psychology. American Psychologist, 25, 144-156. http://doi.org/10.1037/h0029429 
Silverman, I. (1971). Crisis in social psychology: The relevance of relevance. American Psychologist, 26, 583, http://dx.doi.org/10.1037/h0031445.

Simmons, J. P., Nelson, L. D., \& Simonsohn, U. (2011). False-positive psychology: Undisclosed flexibility in data collection and analysis allows presenting anything as significant. Psychological science, 22(11), 1359-1366, DOI:10.1177/0956797611417632.

Simmons, J. P., Nelson, L. D., \& Simonsohn, U. (2018). False-positive citations. Perspectives on Psychological Science, 13(2), 255-259, https://doi.org/10.1177/1745691617698146.

Ståhl, T., \& Van Prooijen, J. W. (2018). Epistemic rationality: Skepticism toward unfounded beliefs requires sufficient cognitive ability and motivation to be rational. Personality and Individual Differences, 122, 155-163, https://doi.org/10.1016/j.paid.2017.10.026.

Taylor, R. J., Burton-Wood, C. G., \& Garry, M. (2017). America was great when nationally relevant events occurred and when Americans were young. Journal of Applied Research in Memory and Cognition, 6(4), 425-433, https://doi.org/10.1016/j.jarmac.2017.05.003.

Weiser, D. A., Niehuis, S., Flora, J., Punyanunt-Carter, N. M., Arias, V. S., \& Baird, R. H. (2018). Swiping right: Sociosexuality, intentions to engage in infidelity, and infidelity experiences on Tinder. Personality and Individual Differences, 133, 29-33, https://doi.org/10.1016/j.paid.2017.10.025.

Witte, E. H., \& Brandt, V. (2011). Social psychological research: The comparison of four journals. Retrieved from http://psydok.sulb.uni-saarland.de/volltexte/2011/2743

Zitek, E. M., \& Jordan, A. H. (2017). Psychological Entitlement Predicts Failure to Follow Instructions. Social Psychological and Personality Science, https://doi.org/10.1177/1948550617729885. 